Nota

\title{
PALHA DE CANA-DE-AÇÚCAR ASSOCIADA AO HERBICIDA TRIFLOXYSULFURON SODIUM + AMETRYN NO CONTROLE DE ROTTBOELLIA EXALTATA $\left({ }^{1}\right)$
}

\author{
ANDERSON RAMOS DE OLIVEIRA $\left({ }^{2 *}\right)$; SILVÉRIO DE PAIVA FREITAS $\left({ }^{3}\right)$
}

\begin{abstract}
RESUMO
O objetivo deste trabalho foi avaliar o potencial da palha da cana-de-açúcar e a associação entre ela e a mistura comercial de trifloxysulfuron sodium + ametryn no controle de Rottboellia exaltata L. O experimento foi desenvolvido na Unidade de Apoio à Pesquisa da UENF, no período de setembro a novembro de 2004. O delineamento experimental utilizado foi o de blocos casualizados com os tratamentos dispostos em esquema fatorial: cinco camadas de palha $\left(0 ; 4 ; 8 ; 12\right.$ e $\left.16 \mathrm{tha}^{-1}\right)$ e cinco doses de trifloxysulfuron sodium + ametryn $(0,0$; 1,$0 ; 1,5 ; 2,0$ e $2,5 \mathrm{~kg} \mathrm{ha}^{-1}$ ), em quatro repetições. Aplicaram-se os herbicidas em pós-emergência, quando as plântulas de R. exaltata estavam com altura entre 5 e $10 \mathrm{~cm}$. Avaliou-se o número de plântulas aos 15, 30, 45 e 60 dias após a aplicação dos herbicidas. Determinou-se o ponto que corresponde à concentração do herbicida que inibe $50 \%$ da planta daninha $\left(I_{50}\right)$. Aos 60 dias, a parte aérea das plantas de R. exaltata foi coletada e transferida para estufa para avaliação da biomassa seca. A interação quantidade de palha e doses de trifloxysulfuron sodium + ametryn foi significativa. Observou-se que camadas de palha com $16 \mathrm{t} \mathrm{ha}^{-1}$ (sem aplicação de herbicida) e 2,5 $\mathrm{kg} \mathrm{ha}^{-1}$ de trifloxysulfuron sodium + ametryn (isolado) foram eficientes no controle de $R$. exaltata. Níveis de palha entre 8 e $12 \mathrm{t} \mathrm{ha}^{-1}$ interceptaram o herbicida, o que elevou o valor de $\mathrm{I}_{50}$, ou seja, a concentração do herbicida para inibir 50\% do crescimento da planta foi maior do que quando se utilizou 4 t de palha.
\end{abstract}

Palavras-chave: cana-crua, capim camalote, manejo de palhada, planta daninha.

\section{ABSTRACT \\ SUGARCANE STRAW COMBINED WITH TRIFLOXYSULFURON SODIUM + AMETRYN FOR ROTTBOELLIA EXALTATA CONTROL}

The objective of this work was to evaluate the sugarcane straw potential and the association between the straw and the commercial mix of the trifloxysulfuron sodium + ametryn to control itchgrass (Rottboellia exaltata L.). The experiment was developed in the Universidade Estadual do Norte Fluminense Darcy Ribeiro (UENF), Campos dos Goytacazes Rio de Janeiro State, Brazil, from September to November 2004. It was carried out in randomized blocks, with the treatments arranged in a factorial scheme: five layers of straw $\left(0 ; 4 ; 8 ; 12 \mathrm{e} 16 \mathrm{t} \mathrm{ha}^{-1}\right)$ and five doses of trifloxysulfuron sodium + ametryn $\left(0,0 ; 1,0 ; 1,5 ; 2,0\right.$ e $\left.2,5 \mathrm{~kg} \mathrm{ha}^{-1}\right)$, with four replications. The herbicide was applied in post-emergence, when weeds ( $R$. exaltata) height was between 5 and $10 \mathrm{~cm}$. Number of weeds was evaluated at 15 , 30, 45 and 60 days after herbicide application. The herbicide concentration that inhibits $50 \%$ of the weed emergency $\left(I_{50}\right)$ was determined. In the sixty day, the itchgrass plants were collected and dry biomass was determined. The interaction between straw quantity and doses of trifloxysulfuron sodium + ametryn was significant. Straw layer of 16 tha $^{-1}$ without herbicide addition was efficient to control $R$. exaltata and the herbicide trifloxysulfuron sodium + ametryn at $2,5 \mathrm{~kg} \mathrm{ha}^{-1}$ used alone was efficient to control this weed. Straw levels between 8 and $12 \mathrm{t} \mathrm{ha}^{-1}$ intercepted the herbicide and consequently, increased the $\mathrm{I}_{50}$ value. In other words, the concentration of the herbicide to inhibit $50 \%$ of the weeds growth was greater when there were 8 and $12 \mathrm{tha}^{-1}$ than when there was $4 \mathrm{tha}^{-1}$ of straw.

Key words: raw sugarcane, itchgrass, straw management, weed.

$\left({ }^{1}\right)$ Recebido para publicação em 14 de junho de 2007 e aceito em 15 de setembro de 2008.

$\left({ }^{2}\right)$ Embrapa Semi-Árido, Rod. BR 428, Km 152, Zona Rural, Caixa Postal 23, 56302-970 Petrolina (PE). E-mail: anderson.oliveira@cpatsa.embrapa.br $\left(^{*}\right)$ Autor correspondente.

$\left({ }^{3}\right)$ Universidade Estadual do Norte Fluminense Darcy Ribeiro - UENF, Av. Alberto Lamego, 2000, 28013-600 Campos dos Goytacazes (RJ). E-mail: silverio@uenf.br 


\section{Introdução}

A colheita da cana-de-açúcar, quando realizada no sistema de cana-crua, ou seja, colheita sem queima da palhada, pressupõe maior deposição da palha sobre o solo, o que interfere com a germinação e o desenvolvimento de plantas daninhas.

A inibição da germinação ou do desenvolvimento das plantas daninhas pode ocorrer por efeitos físicos, biológicos ou de natureza alelopática (Hilhorst e Toorop, 1997; Medeiros e Christoffoleti, 2001; Pitelli e Durigan, 2001). O efeito físico pode ser evidenciado pelo baixo número de plantas daninhas verificado em áreas cobertas por palha, pois esta interfere na quantidade de radiação solar incidente, na qualidade do comprimento de luz e na manutenção da temperatura do solo com menores oscilações ou constitui-se em barreira física que impede o desenvolvimento das plantas (Pitelli e Durigan, 2001; AzANiA et al., 2002; Correia et al., 2006).

O efeito biológico pode ser observado pela instalação de densa e diversificada microbiocenose na camada superficial do solo. Nesta microbiota há grande quantidade de organismos que podem utilizar sementes e plântulas de espécies daninhas como fonte de energia (Correia e Rezende, 2002; Pitelli, 2003).

O efeito alelopático, por sua vez, pode ser percebido pela liberação de substâncias do metabolismo secundário das plantas durante o processo de decomposição, as quais impedem ou reduzem o desenvolvimento das plantas daninhas (VIDAL e BAUMAN, 1996; Anaya, 1999; Theisen et al., 2000; Correia et al., 2005; ToKuRA e Nóbrega, 2006). O efeito alelopático da palha da cana-de-açúcar na germinação e no desenvolvimento de plantas daninhas foi constatado em estudos de SÁNCHEZ-MoReIRA et al., 2003; SINGH et al., 2004; SAmpietro e VAttuone, 2006 e Viator et al., 2006.

Dentre as plantas daninhas que mais competem com a lavoura canavieira destaca-se o capim-camalote (Rottboellia exaltata L.) que, em densidades maiores que 10 plantas por $\mathrm{m}^{2}$, não permite o desenvolvimento pleno das plantas de canade-açúcar. Esta espécie é muito vigorosa e prolífica, sendo capaz de emitir até 100 perfilhos e suas sementes ficam em dormência no solo por até quatro anos (Sharma e Zelaya, 1986). De acordo com Arévalo (2001), o capim-camalote prefere as mesmas condições ecológicas que as plantas de cana-de-açúcar, tais como: alta temperatura $\left(27^{\circ} \mathrm{C}\right)$ e alta umidade $(>1500$ $\mathrm{mm}$ de chuva por ano). A convivência de populações de $R$. exaltata na cultura da cana-de-açúcar provoca perdas no rendimento. O manejo é oneroso, devido à necessidade de se utilizar até seis aplicações de herbicidas durante o ciclo da cultura.
O uso de herbicidas em áreas com cana-deaçúcar é uma prática bastante difundida nas áreas canavieiras de todo o país. A mistura pronta de trifloxysulfuron sodium + ametryn quando utilizada, em pós-emergência, em lavouras de cana-de-açúcar é eficaz no controle das principais plantas daninhas, sendo uma mistura herbicídica de grande potencial para o controle do capim-camalote. $\mathrm{O}$ trifloxysulfuron sodium + ametryn inibe a formação de proteínas e o desenvolvimento das plantas suscetíveis, causando amarelecimento das folhas, interrupção do crescimento e morte em até três semanas após a aplicação (Oliveira et al., 2001).

A utilização da palha da cana-de-açúcar associada ao herbicida pode representar importante método de controle do capim-camalote, reduzindo as doses do herbicida.

Este trabalho teve como objetivo avaliar o potencial de utilização da palha de cana-de-açúcar e a interação entre ela e a mistura comercial de trifloxysulfuron sodium + ametryn no controle de capim-camalote (Rottboellia exaltata L.).

\section{Material e Métodos}

O experimento foi desenvolvido na área de apoio à pesquisa do Centro de Ciências e Tecnologias Agropecuárias da Universidade Estadual do Norte Fluminense Darcy Ribeiro, em Campos dos Goytacazes (RJ), no período de setembro a novembro de 2004.

Segundo o sistema Köppen, o clima da região é classificado como $\mathrm{Aw}$, isto é, clima quente e úmido, com temperatura do mês mais frio superior a $18{ }^{\circ} \mathrm{C} \mathrm{e}$ a temperatura média anual de $24{ }^{\circ} \mathrm{C}$, sendo a amplitude térmica anual muito pequena, com temperatura média do mês mais frio de $21^{\circ} \mathrm{C}$ e o mais quente de $27^{\circ} \mathrm{C}$. A precipitação pluvial anual média está em torno de $1.023 \mathrm{~mm}$, concentrando-se, principalmente, de outubro a janeiro.

O delineamento experimental foi o de blocos casualizados em esquema fatorial $(5 \times 5)$, com quatro repetições. O primeiro fator constituiu-se de cinco coberturas de palha de cana-de-açúcar $(0 ; 4 ; 8 ; 12$ e $\left.16 \mathrm{t} \mathrm{ha}^{-1}\right)$ e o segundo, de cinco doses de trifloxysulfuron sodium + ametryn $(0,0 ; 1,0 ; 1,5 ; 2,0$ e 2,5 kg ha-1).

Foram coletadas sementes de capim-camalote (R. exaltata), em áreas das Usinas Santa Cruz e Sapucaia, ambas localizadas no município de Campos dos Goytacazes (RJ). As sementes foram levadas para o laboratório, onde foram classificadas por peso em um soprador e em seguida testadas quanto ao 
potencial germinativo. Após a realização do teste, verificou-se que as sementes germinaram, em média, $15 \%$. Com base no poder germinativo, calculou-se a massa (g) de sementes para que houvesse, aproximadamente, 200 sementes viáveis por parcela. Cada parcela experimental possuía uma área de 1,2 $\mathrm{m}^{2}(1,0 \mathrm{~m} \times 1,2 \mathrm{~m})$, distando-se uma das outras em 1 m. A área total do experimento foi de $448,8 \mathrm{~m}^{2}$.

Após a semeadura, foram depositadas sobre o solo as quantidades específicas de palha de canade-açúcar recém-colhidas da variedade RB 72454, referente a cada tratamento. A palha foi obtida inteira através de colheita manual da cana-de-açúcar em área de produção comercial da Usina Santa Cruz S.A.

A aplicação das diferentes doses dos herbicidas foi realizada 20 dias após a semeadura de R. exaltata, quando a altura das plântulas era de 5 a $10 \mathrm{~cm}$. Utilizou-se pulverizador pressurizado com $\mathrm{CO}_{2}$ a pressão constante de $3,5 \mathrm{kgf} \mathrm{cm}^{-2}$, com haste provida de um bico tipo leque XR 80 03, consumo de calda de, aproximadamente, $250 \mathrm{~L} \mathrm{ha}^{-1}$. Foi adicionado espalhante adesivo Agral ${ }^{\circledR}(0,2 \%)$ em todos os tratamentos herbicidas. No momento da aplicação, constatou-se temperatura média de $20{ }^{\circ} \mathrm{C}$, umidade relativa de $79 \%$, velocidade do vento de $2 \mathrm{~m} \mathrm{~s}^{-1}$ e solo pouco úmido, com umidade $70 \%$ menor que a capacidade de campo.

Avaliou-se o número de plantas sobreviventes aos 15, 30, 45 e 60 dias após a aplicação (DAA) dos herbicidas. Aos $60 \mathrm{DAA}$, as plantas de R. exaltata foram cortadas rente ao solo e levadas para estufa com circulação forçada de ar regulada à temperatura de $70{ }^{\circ} \mathrm{C}$ até atingirem massa constante para determinação da biomassa epígea seca.

As variáveis foram submetidas à análise de variância por meio do teste $\mathrm{F}$ a $5 \%$ de probabilidade. Foram ajustados modelos não-lineares - logístico e sigmoidal - nas estimativas dos parâmetros das análises de regressão. $\mathrm{O}$ modelo logístico possui três parâmetros e o modelo sigmoidal, quatro parâmetros, sendo $\mathrm{X}_{0}$ o ponto de inflexão da curva, que corresponde ao valor de $\mathrm{I}_{50}$, ou seja, é a concentração do produto que inibe $50 \%$ do crescimento do bioindicador (Streibig et al., 1993). Os dados foram previamente transformados em $\sqrt{x+1}$, com o objetivo de proporcionar distribuição normal.

Modelo logístico:

$$
\hat{y}=\frac{a}{1+\left(\frac{x}{x_{0}}\right)^{b}}
$$

Modelo sigmoidal:

$$
\hat{y}=y^{0}+\frac{a}{1+e^{-\left(\frac{x-x_{0}}{b}\right)}}
$$

\section{Resultados e Discussão}

A interação quantidade de palha e doses de trifloxysulfuron sodium + ametryn foi significativa. Quando se utilizou o maior nível de palha, observou-se que o controle da $R$. exaltata foi eficiente, pois não houve emergência de plantas, independentemente da dose de herbicida utilizada. Permite-se afirmar que a utilização de $16 \mathrm{t} \mathrm{ha}^{-1}$ de palha foi suficiente para o controle da planta daninha, não havendo a necessidade da aplicação de herbicida. Por outro lado, apenas a utilização de $2,5 \mathrm{~kg} \mathrm{ha}^{-1}$ de herbicida foi suficiente para o controle de $R$. exaltata independentemente do nível de palha testado.

Equações de regressão (Tabela 1) indicaram que na ausência de palha, doses de 1,5 a 2,5 kg ha-1 da mistura comercial de trifloxysulfuron sodium + ametryn, controlaram $R$. exaltata, reduzindo os escapes aos 15, 30, 45 e 60 DAA. Freitas et al. (2004) observaram reduções na emergência de $R$. exaltata com a aplicação de 1,75 e $2,0 \mathrm{~kg} \mathrm{ha}^{-1}$ de trifloxysulfuron sodium + ametryn. A dose de $2,0 \mathrm{~kg} \mathrm{ha}^{-1}$ proporcionou controle superior a $90 \%$ de R. exaltata, corroborando os resultados encontrados por MORENo (1996), trabalhando com herbicidas do grupo químico das sulfuniluréias.

A utilização de 1,0 e 1,5 $\mathrm{kg} \mathrm{ha}^{-1}$ do herbicida, na presença de 8 ou 12 t de palha por hectare proporcionou maior controle das plantas de capimcamalote, cujos valores variaram de 1 a 5 plantas por $\mathrm{m}^{2}$, enquanto com 0 e $4 \mathrm{t} \mathrm{ha}^{-1}$ de palha o número de plantas variou de 3 a 10 plantas $\mathrm{m}^{-2}$.

Estes resultados assemelham-se aos constatados por Medeiros (2001), que alcançou controle de quatro espécies monocotiledôneas utilizando $15 \mathrm{t} \mathrm{ha}^{-1}$ de palha de cana-de-açúcar. Concorda, também, com o trabalho de Gravena et al. (2004), que, ao estudarem a associação da palha da cana-de-açúcar como a mistura comercial de trifloxysulfuron sodium + ametryn, observaram que a utilização isolada da palha da cana-de-açúcar (10 ou $15 \mathrm{t} \mathrm{ha}^{-1}$ ) ou a mistura dos herbicidas trifloxysulfuron sodium + ametryn $\left(1,75\right.$ ou $\left.2,0 \mathrm{~kg} \mathrm{ha}^{-1}\right)$ controlou quase totalmente a gramínea Brachiaria plantaginea (Link) Hitchc.

Resultados similares foram verificados por CoRreia e Durigan (2004) que observaram reduções na emergência de plântulas da família Poaceae (Brachiaria decumbens Stapf e Digitaria horizontalis Willd) quando foram utilizadas quantidades de 10 e $15 \mathrm{t} \mathrm{ha}^{-1}$ de palha de cana-de-açúcar. Esses autores observaram, ainda, reduções na biomassa seca em $64 \%$. 


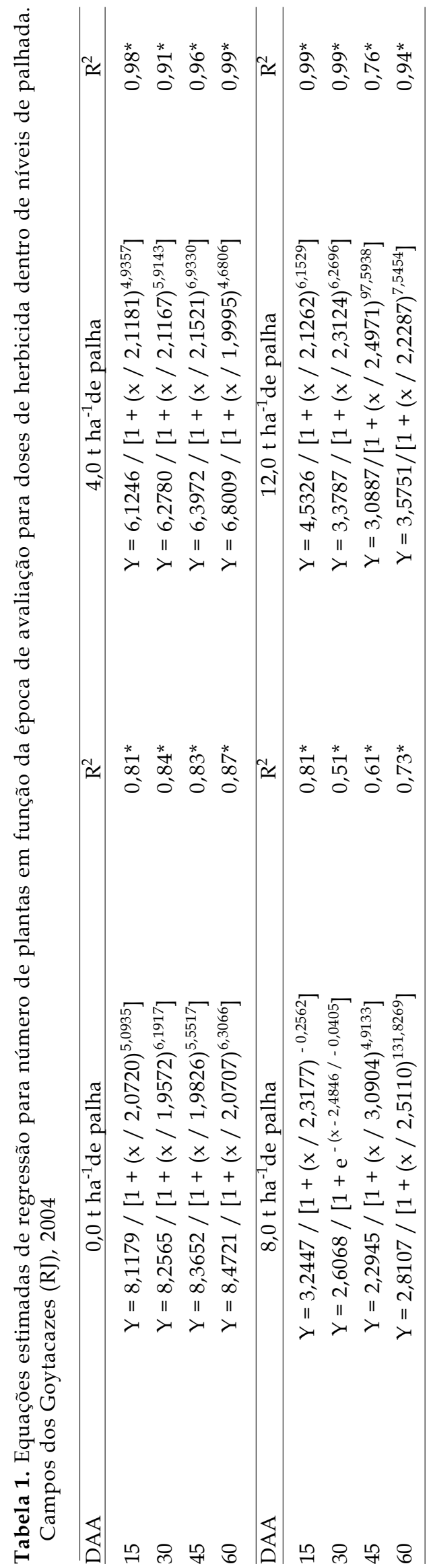

Quanto ao controle químico de Cyperus rotundus L., com e sem cobertura do solo pela palha de cana-de-açúcar, DURIGAN et al. (2004) verificaram que a palha da cana reduziu a infestação de $C$. rotundus, porém, não foi suficiente para evitar grandes densidades da espécie. SILVA et al. (2003) observaram que 16 e 20 tha $^{-1}$ de palha de cana-de-açúcar proporcionaram menor quantidade de plantas de $C$. rotundus emersas.

$\mathrm{Na}$ ausência de palha, o $\mathrm{I}_{50}$ (concentração do herbicida que atingiu $50 \%$ de resposta) foi de 2,$07 ; 1,96$; 1,98 e $2,07 \mathrm{~kg} \mathrm{ha}^{-1}$ para $15,30,45$ e 60 DAA respectivamente. Constatou-se que na presença de $8 \mathrm{t}$ $\mathrm{ha}^{-1}$ de palha, este parâmetro aumentou para 2,31;2,48; 3,09 e $2,51 \mathrm{~kg} \mathrm{ha}^{-1} \mathrm{e}$, com a utilização de $12 \mathrm{t} \mathrm{ha}^{-1} \mathrm{o} \mathrm{I}_{50}$ variou de 2,12 a 2,49 $\mathrm{kg} \mathrm{ha}^{-1}$, indicando que a presença de maiores níveis de palha pode interceptar o herbicida, sendo necessárias doses maiores para que ocorra inibição de $50 \%$ das plantas de R. exaltata.

Na figura 1 são apresentados os valores de biomassa seca da parte aérea das plantas de $R$. exaltata aos 60 DAA. Observou-se que na presença de $4 \mathrm{t}$ de palha, a dose de trifloxysulfuron sodium + ametryn que promoveu $50 \%$ de redução da biomassa de $R$. exaltata foi de $2,27 \mathrm{~kg} \mathrm{ha}^{-1}$ do herbicida. Notase, que apesar de menores números de plantas nos níveis de palha de 8 e 12 tha $^{-1}$, o $\mathrm{I}_{50}$ aumentou para 2,93 e 2,68 $\mathrm{kg} \mathrm{ha}^{-1}$ do herbicida, respectivamente. Este aumento, provavelmente, ocorreu devido à interceptação do herbicida pela palha.

A associação do herbicida-palha pode resultar em menor eficiência de controle da planta daninha, pois a palha pode reter o herbicida. Assim, plântulas que germinaram e não ultrapassaram a camada de palha podem sobreviver visto que há menor exposição ao herbicida. A mistura trifloxysulfuron sodium + ametryn, quando não interceptada pela camada de palha, proporciona efeito residual no solo (VIVIAN et al., 2007) garantindo maior controle de $R$. exaltata. Monguero et al. (2007) observaram diferenças significativas na eficácia dos herbicidas imazapyr, trifloxysulfuron sodium + ametryn e diuron + hexazinone pela interceptação da camada de palha, mostrando redução da eficácia a partir de $15 \mathrm{t} \mathrm{ha}^{-1}$ de palha de cana-de-açúcar. Segundo Velini e Negrisoli (2000), em uma camada de palha de canade-açúcar de $1 \mathrm{t} \mathrm{ha}^{-1}$, apenas $35,5 \%$ da calda pulverizada atinge o solo. Essa interceptação atinge 99,4 e $99,5 \%$, para 10 e $15 \mathrm{t} \mathrm{ha}^{-1}$ respectivamente. Trabalho de Fornarolli et al. (1998) com herbicida atrazine demonstrou a retenção do herbicida pela palha de cana-de-açúcar. Por outro lado, estudo de HERNANDEZ et al. (2001) com o herbicida imazapic em solos cobertos com a palha da cana-de-açúcar não demonstrou retenção do herbicida pela palha. 

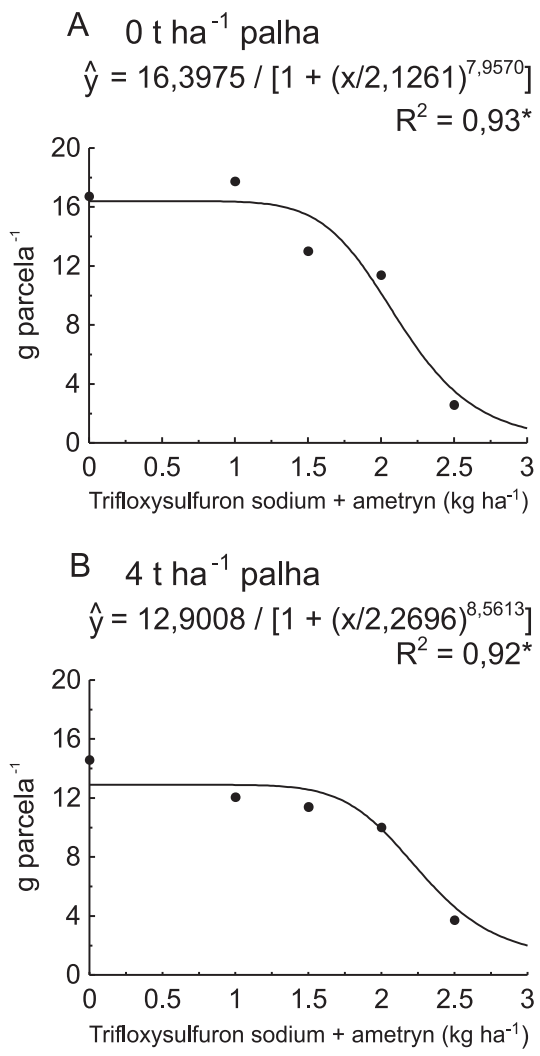

C $8 \mathrm{tha}^{-1}$ palha
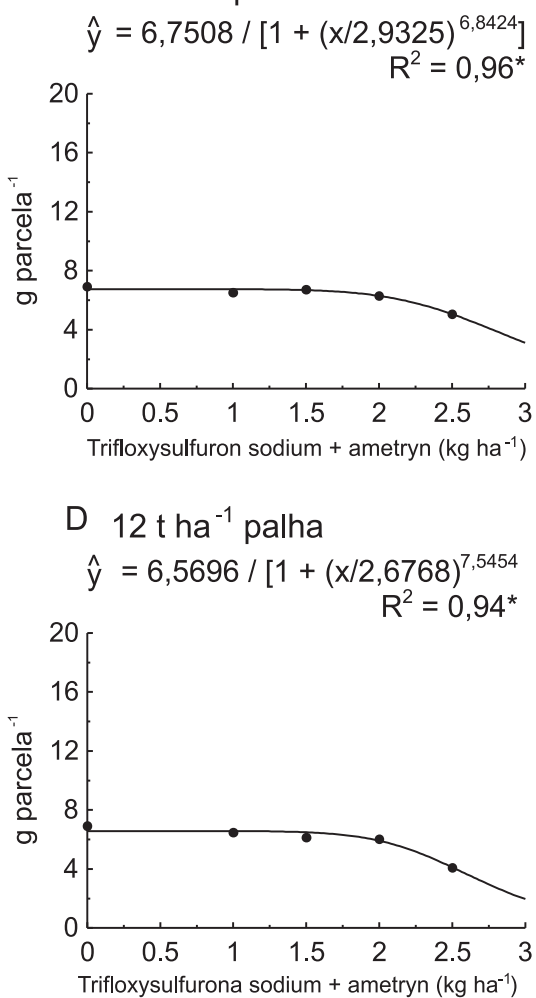

Figura 1: Efeito de doses crescentes da mistura trifloxysulfuron sodium + ametryn na biomassa seca da parte aérea de plantas de $R$. exaltata aos 60 DAA, em diferentes níveis de palha de cana-de-açúcar. Campos dos Goytacazes (RJ), 2004.

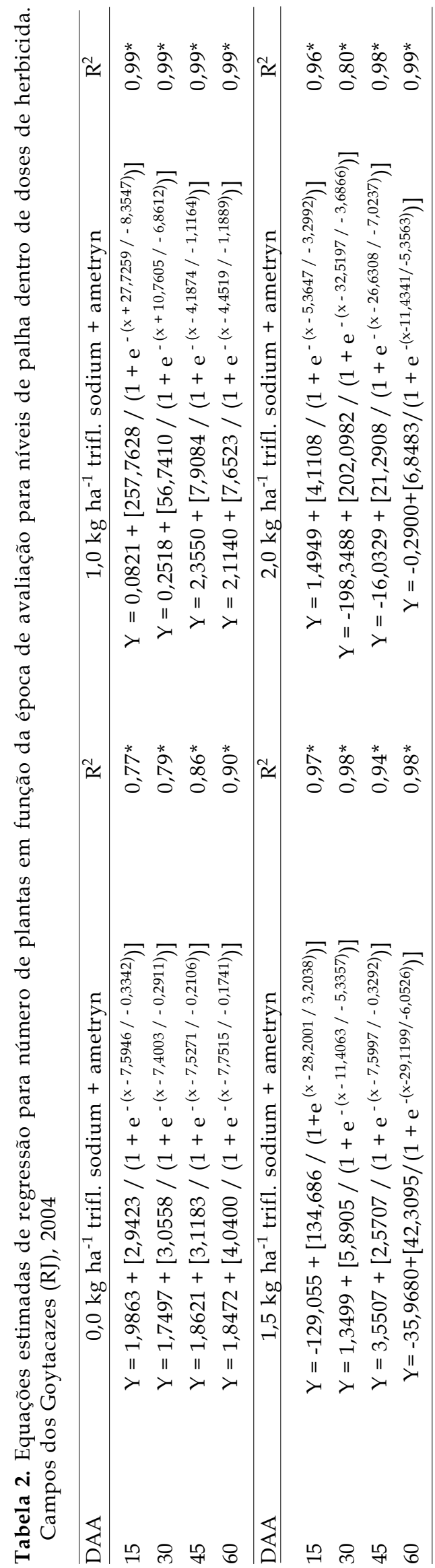

Bragantia, Campinas, v.68, n.1, p.187-194, 2009 

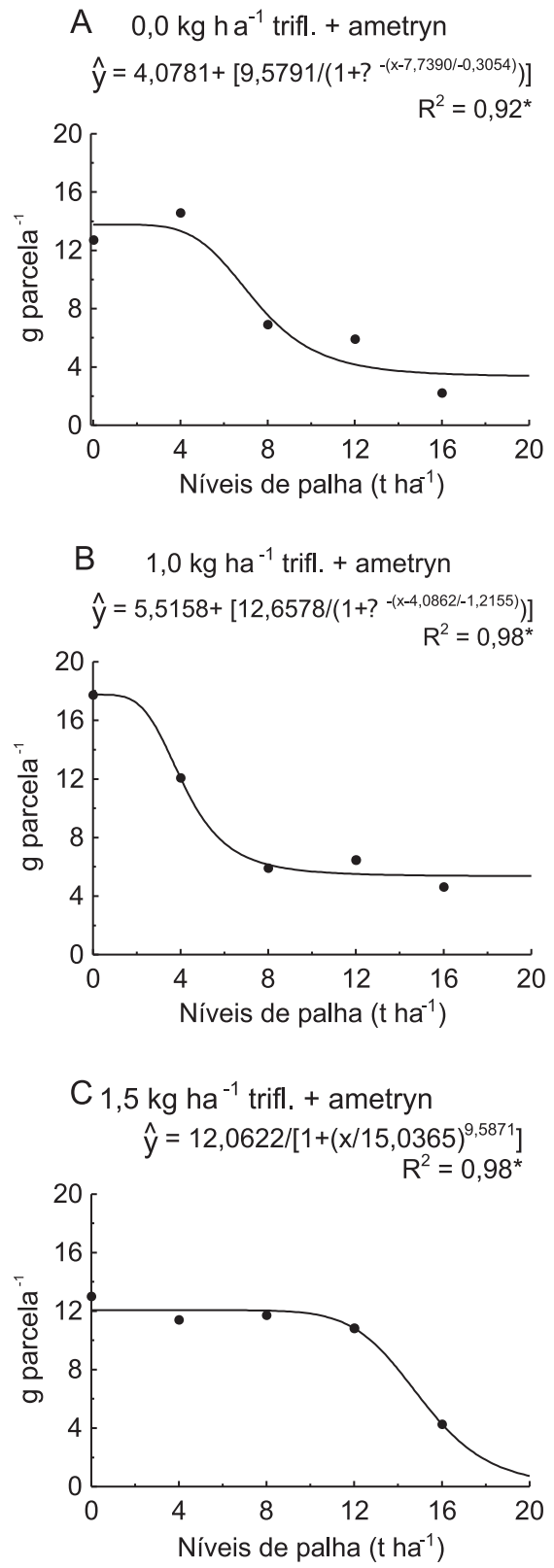

D $2,0 \mathrm{~kg} \mathrm{ha}^{-1}$ trifl. + ametryn

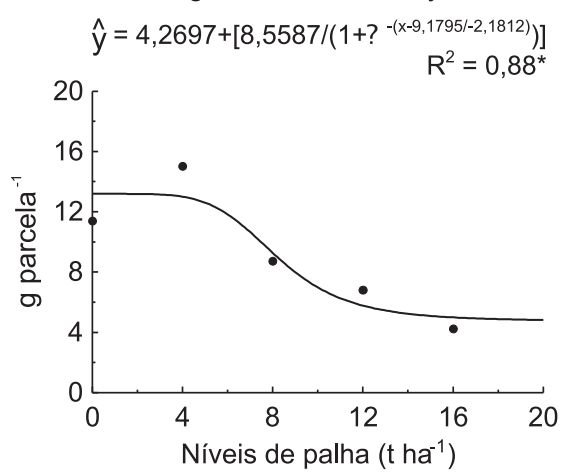

Figura 2. Efeito de diferentes níveis de palha na biomassa seca da parte aérea de plantas de $R$. exaltata aos 60 DAA, em diferentes doses de herbicida. Campos dos Goytacazes (RJ), 2004.
$\mathrm{Na}$ tabela 2 são apresentadas equações estimadas de regressão referentes ao efeito da interação dos níveis de palha dentro do fator dose, para número de plantas. Observou-se que o nível de palha de $4 \mathrm{t}$ $\mathrm{ha}^{-1}$, na ausência de herbicidas, permitiu maior ocorrência de plantas daninhas que o nível $0 \mathrm{t} \mathrm{ha}^{-1}$ de palha.

Essa evidência atesta que a utilização de pequenas quantidades de palha pode estimular a germinação das sementes da planta daninha por proporcionar ambiente mais úmido e menores oscilações de temperatura, sem impedir totalmente a passagem da luz. Por outro lado, quando se deixa o solo totalmente descoberto, a baixa umidade na superfície do solo e a maior temperatura não favorecem a germinação das sementes. De acordo com GRAVENA et al. (2004), em áreas onde a deposição de palha de cana-de-açúcar seja desuniforme é possível a ocorrência de plantas daninhas, o que exige a adoção de práticas de controle.

Verificou-se, ainda, que a aplicação de 1,0 kg $\mathrm{ha}^{-1}$ da mistura formulada dos herbicidas na ausência de palha não foi eficiente no controle do $R$. exaltata. Maiores reduções foram observadas com níveis de 8; 12 e $16 \mathrm{t} \mathrm{ha}^{-1}$. Quando se utilizou níveis de palha de 8 e 12 t ha $^{-1}$ juntamente com a dose de $2,0 \mathrm{~kg} \mathrm{ha}^{-1}$ de trifloxysulfuron sodium + ametryn notaram-se reduções no número de plantas de $R$. exaltata (2 a 3 plantas $\mathrm{m}^{-2}$ ).

Como apresentado na figura 2, os níveis de palha próximos a $4 \mathrm{t} \mathrm{ha}^{-1}$ possibilitaram maior escape de plantas e, consequentemente, maior biomassa seca das plantas de capim-camalote (R. exaltata).

A interação $1,5 \mathrm{~kg} \mathrm{ha}^{-1}$ de trifloxysulfuron sodium + ametryn e níveis de palha de até $12 \mathrm{t} \mathrm{ha}^{-1}$ resultaram em biomassa seca semelhante à aplicação isolada de $1,5 \mathrm{~kg} \mathrm{ha}^{-1}$ do herbicida.

\section{Conclusões}

1. A quantidade de palha de $16 \mathrm{t} \mathrm{ha}^{-1}$ controlou de forma eficiente a espécie $R$. exaltata, independentemente da utilização de herbicidas.

2. A dose de $2,5 \mathrm{~kg} \mathrm{ha}^{-1}$ da mistura comercial de trifloxysulfuron sodium + ametryn proporcionou controle eficiente de $R$. exaltata independente da presença de palha.

3. Níveis de palha entre 8 e $12 \mathrm{t} \mathrm{ha}^{-1}$ interceptaram o herbicida, aumentando o valor de $\mathrm{I}_{50}$, ou seja, a concentração do herbicida para inibir $50 \%$ do crescimento da planta foi maior do que quando se utilizou 4 t de palha. 


\section{REFERÊNCIAS}

ANAYA, A.L. Allelopathy as a tool in the management of biotic resources in agroecosystems. Critical Reviews in Plant Sciences, Boca Raton, v.18, n.6, p.697-739, 1999.

ARÉVALO, R.A. Rottboellia exaltata (capim-camalote) em cana-de-açúcar. Piracicaba: edição do autor, 2001.

AZANIA, A.A.P.M.; AZANIA, C.A.M.; GRAVENA, R.; PAVANI, M.C.M.D.; PITELLI, R.A. Interferência da palha de cana-de-açúcar (Saccharum spp.) na emergência de espécies de plantas daninhas da família Convolvulaceae. Planta Daninha, Viçosa, v. 20, n. 2, p. 207-212, 2002.

CORREIA, N.M.; DURIGAN, J.C. Emergência de plantas daninhas em solo coberto com palha de cana-de-açúcar. Planta Daninha, Viçosa, v. 22, n. 1, p. 11-17, 2004.

CORREIA, N.M.; DURIGAN, J.C.; KLINK, U.P. Influência do tipo e da quantidade de resíduos vegetais na emergência de plantas daninhas. Planta Daninha, Viçosa, v. 24, n.2, p. 245$253,2006$.

CORREIA, N.M.; REZENDE, P.M. Manejo integrado de plantas daninhas na cultura da soja. Lavras: Editora UFLA, 2002. 55 p. (Boletim Agropecuário, 51)

CORREIA, N.M.; SOUZA, I.F.; KLINK, U.P. Palha de sorgo associada ao herbicida imazamox no controle de plantas daninhas na cultura da soja em sucessão. Planta Daninha, Viçosa, v. 23, n. 3, p. $483-489,2005$.

DURIGAN, J.C.; TIMOSSI, P.C.; LEITE, G.J. Controle químico da tiririca (Cyperus rotundus), com e sem cobertura do solo pela palha de cana-de-açúcar. Planta Daninha, Viçosa, v. 22, n. 1, p. 127-135, 2004.

FORNAROLLI, D.A.; RODRIGUES, B.N.; LIMA, J.; VALÉRIO, M.A. Influência da cobertura morta no comportamento do herbicida atrazine. Planta Daninha, Viçosa, v. 16, n. 2, p. 97107,1998

FREITAS, S.P.; OLIVEIRA, A.R.; FREITAS, S.J.;SOARES, L.M.S. Controle químico de Rottboellia exaltata em cana-de-açúcar. Planta Daninha, Viçosa, v. 22, n. 3, p. 461-466, 2004.

GRAVENA, R.; RODRIGUES, J.P.R.G.; SPINDOLA, W.; PITELLI, R.A.; ALVES, P.L.C.A. Controle de plantas daninhas através da palha de cana-de-açúcar associada à mistura dos herbicidas trifloxysulfuron sodium + ametrina. Planta Daninha, Viçosa, v. 22, n. 3, p. 419-427, 2004.

HERNANDEZ, D.D.; ALVES, P.L.C.A.; MARTINS, J.V.F. Influência do resíduo de colheita de cana-de-açúcar sem queima sobre a eficiência dos herbicidas imazapic e imazapic + pendimenthalin. Planta Daninha, Viçosa, v. 19, n. 3, p. 419426, 2001.

HILHORST, H.W.M.; TOOROP, P.E. Review on dormancy, germinability, and germination in crop and weed seeds. Advances in Agronomy, San Diego, v. 61, p. 112-165, 1997.
MEDEIROS, D. Efeitos da palha de cana-de-açúcar (Saccharum spp.) sobre o manejo de plantas daninhas e dinâmica do banco de sementes. 2001. 126 f. Dissertação (Mestrado em Fitotecnia) - Escola Superior de Agricultura “Luiz de Queiroz”, Piracicaba, 2001.

MEDEIROS, D.; CHRISTOFFOLETI, P.J. Efeito da palha de cana-de-açúcar em áreas de colheita mecanizada sem queima sobre a infestação de plantas daninhas e eficácia de herbicidas. In: PRADO, R.; JORRÍN, J.V. Uso de herbicidas en la agricultura del siglo XXI. Córdoba: Universidad de Córdoba, 2001. p. 599-605.

MONQUERO, P.A., AMARAL, L.R., SILVA, A.C.; SILVA, P.V.; BINHA, D.P. Eficácia de herbicidas em diferentes quantidades de palha de cana-de-açúcar no controle de Euphorbia heterophylla. Planta Daninha, Viçosa, v. 25, n. 3, p. 613-619, 2007.

MORENO, B. Efeito de vários herbicidas sobre el control de malezas em maíz (zea mays 1.) y su persistencia en el suelo. 1996. 152f. Tese (Mestrado em Agronomia) - Universidad Central de Venezuela, Maracy, 1996.

OLIVEIRA JÚNIOR., R.S., CONSTANTIN, J., SOARES, J. E., HERNANDES, A. I. F., MARCHIORI JÚNIOR., O. Trifloxysulfuron-sodium: nova opção para o controle seletivo de plantas daninhas na cultura do algodão. Revista Brasileira de Oleaginosas e Fibrosas, Campina Grande, v. 5, n. 2, p. 345$354,2001$.

PITELLI, R.A. Impactos do sistema de plantio direto na palha sobre as comunidades infestantes. Jornal Consherb, São Paulo, v. 2, n. 9, p. 1-3, 2003.

PITELLI, R.A.; DURIGAN, J.C. Ecologia das plantas daninhas no sistema plantio direto. In: ROSSELLO, R.D. Siembra directa en el cono sur. Montevideo: Procisur, 2001. p.203-210.

SAMPIETRO, D.A.; VATTUONE, M.A. Sugarcane straw and its phytochemicals as growth regulators of weed and crop plants. Plant Growth Regulation, Dordrecht, v. 48, n. 1, p. 21-27, 2006.

SÁNCHEZ-MOREIRA, A.M.; WEISS, O.A.; REIGOSA-ROGER, M.J. Allelopathic evidence in the Poaceae. Botanical Reviews, Vigo, v. 69, n. 3, p. 300-319, 2003.

SHARMA, D., ZELAYA, O. Competition and control of itchgrass (Rottboellia exaltata) in maize (Zea mays). Tropical Pest Management, London, v. 32, p. 101-104, 1986.

SILVA, J.R.V.; COSTA, N.V.; MARTINS, D. Efeito da palhada de cultivares de cana-de-açúcar na emergência de Cyperus rotundus. Planta Daninha, Viçosa, v. 21, n. 3, p. 375-380, 2003.

SINGH, H.P.; BATISH, D.R.; KOHLI, R.K. Allelopathic interactions and allelochemicals: new possibilities for sustainable weed management. Critical Reviews in Plant Sciences, Boca Raton, v. 22, n. 3/4, p. 239-311, 2004.

STREIBIG, J.C.; RUDEMO, M.; JENSEN, J. E. Dose-response curves and statistical models: In: STREIBIG, J.C.; KUDSK, P. (Org.). Herbicide Biossays. Flórida: CRC Press, 1993. p. 29-55. 
THEISEN, G.; VIDAL, R.A.; FLECK, N.G. Redução da infestação de Brachiaria plantaginea em soja pela cobertura do solo com palha de aveia-preta. Pesquisa Agropecuária Brasileira, Brasília, v. 35, n. 4, p. 753-756, 2000.

TOKURA, L.K.; NÓBREGA, L.H.P. Alelopatia de cultivos de cobertura vegetal sobre plantas infestantes. Acta Scientiarum Agronomy, Maringá, v. 28, n. 3, p. 379-384, 2006.

VELINI, E.D.; NEGRISOLI, E. Controle de plantas daninhas em cana crua. In: CONGRESSO BRASILEIRO DA CIÊNCIA DAS PLANTAS DANINHAS, 22., 2000, Foz do Iguaçu. Palestras... Foz do Iguaçu: SBCPD, 2000, p. 148-164.

VIATOR, R.P.; JOHNSON, R.M.; GRIMM, C.C.; RICHARD JUNIOR, E.P. Allelopathic, autotoxic, and hormetic effects of postharvest sugarcane residue. Agronomy Journal, Madison, v. 98, p. 1526-1531, 2006.

VIDAL, R.A.; BAUMAN, T.T. Surface wheat (Triticum aestivum) residues, giant foxtail (Setaria faberi), and soybean (Glycine max) yield. Weed Science, Champaign,v. 44, n.5, p.939-943, 1996.

VIVIAN, R.; QUEIROZ, M. E. L. R.; REIS, M. R.; GUIMARAES, A. A.; JAKELAITIS, A.; CARNEIRO, P. M.; SILVA, A. A. persistência e lixiviação de ametryn e trifloxysulfuron-sodium em solo cultivado com cana-de-açúcar. Planta Daninha, Viçosa, v. 25, n. 1 , p. 111-124, 2007. 